\title{
MARCO JURÍDICO EN LOS PROCESOS DE PAZ MIRADA HISTÓRICA* 1950 - 2006
}

\author{
Judicial framework in the processes of peace \\ Historical View 1950-2006
}

\author{
Jorge Carvajal Martínez**
}

Fecha de entrega: 6 de febrero de 2007 Fecha de aprobación: 11 de mayo de 2007

Fecha de evaluación: 7 de junio de 2007

\section{Resumen}

El texto presenta las vías jurídicas que los distintos gobiernos de Colombia han implementado para viabilizar los procesos de negociación y reinserción de los grupos armados no estatales, desde un punto de vista histórico, jurídico y político en el marco del conflicto armado que vive Colombia.

\section{Palabras clave}

Amnistía, indulto, negociación, desmovilización, ley y paz, conflicto armado.

\footnotetext{
* Avance de investigación tesis de doctorado la cual fue presentada como ponencia, en el Marco de la Escuela de Verano (Julio 2006) sobre el tema "La Sociología Jurídica al servicio de los Derechos Humanos en los procesos de paz", organizado por el Instituto Internacional de Sociología de OÑATI (País Vasco- España).

** Docente Facultad de Derecho Universidad Santo Tomás. Miembro de la línea de investigación Derecho y Sociedad Categoría A de Colciencias. Correo electrónico: jorgecarvajal@correo.usta.edu.co
} 


\begin{abstract}
This text presents - from a historical, juristic and political perspective - the juristic strategies implemented by different Colombian governments in order to make feasible, within the framework of Colombia's armed conflict, the negotiation and reinsertion processes with the non state armed groups.
\end{abstract}

\title{
Key words
}

Amnesty, oblivion, negotiation, demobilization, law and peace, armed conflict.

\section{PRESENTACIÓN}

El artículo tiene como objetivo analizar la evolución del marco normativo que en la historia reciente del país se ha construido, con el fin de establecer procesos de negociación con los grupos armados no estatales. Para tal efecto, dividiremos nuestra intervención en cuatro partes. La primera, tratará los antecedentes históricos del conflicto armado con el objetivo de entender las bifurcaciones ideológicas y políticas que la lucha armada ha tenido en nuestro país, la complejidad de los orígenes del conflicto mismo y las amnistías e indultos que se dieron en el marco del conflicto y negociación con los grupos insurgentes, fundamentalmente aquellas otorgadas a finales de los años ochenta. La segunda parte, analizará las actuales dinámicas de la guerra, haciendo énfasis en esta parte de los costos que la guerra ha ocasionado a la sociedad, en particular señalaremos como la sociedad civil es victima del conflicto armado, lo cual genera connotaciones importantes para tener en cuenta en cualquier proceso de negociación. En el último apartado, haremos una reseña de los principales aspectos nor- mativos y trataremos en mayor detalle el análisis de la "Ley de Justicia y Paz", marco jurídico que ha sido creado bajo el gobierno de Álvaro Uribe Vélez poniendo el énfasis en los aspectos de verdad, justicia y reparación.

Para la realización del presente trabajo, se recurrió a diferentes tipos de fuentes, se analizaron bancos de datos sobre la violencia, fuentes legislativas y documentos de investigación sobre el conflicto armado. El periodo abarca los últimos cuarenta años, esto con el fin de establecer un escenario que permita dar una explicación de los éxitos y fracasos de los procesos de negociación.

\section{ANTECEDENTES DEL CONFLICTO Y LA VIOLENCIA SOCIOPOLÍTICA EN COLOMBIA}

Podríamos comenzar por decir que Colombia ha sido un país que históricamente ha resuelto sus disputas políticas y sociales a través de la confrontación armada. Así lo demuestran las innu- 
merables guerras civiles ocurridas a todo lo largo del siglo XIX, y los conflictos heredados del siglo $X X$, que aún continúan hasta el presente. Un ejemplo de lo anterior, fueron las continuas guerras civiles desarrolladas durante el siglo XIX, estas, se caracterizaron por la confrontación entre liberales y conservadores con el fin de imponer un modelo político y social, este proceso de violencia finalizó con la trágica guerra de los 1000 días (1899-1903).

Alrededor de 1940, en Colombia se inician nuevamente los enfrentamientos armados, reaparecen las luchas partidistas entre liberales y conservadores en la pugna por imponer modelos e intereses que no necesariamente recogen las necesidades de la sociedad. El detonante de esta nueva confrontación es el asesinato, en 1948, del líder liberal Jorge Eliécer Gaitán, quien promovía un discurso modernizador y reformista del Estado. De forma simultánea afloraron grupos de ascendencia campesina que desde la década de 1930 reivindicaban como plataforma de sus luchas, causas sociales relacionadas fundamentalmente con el derecho a la tierra y la implementación de una reforma agraria que impidiera la acumulación de la propiedad de la tierra como práctica latifundista y la consecuente necesidad de redistribuir la misma en interés y en beneficio de las comunidades. Estas luchas con el tiempo van adquiriendo un sentido político, particularmente con la recepción de doctrinas marxistas o de corte socialista. Estas manifestaciones armadas se dieron inicialmente a través de las "autodefensas campesinas", primeros focos de guerrilla liberal existentes en los Llanos Orientales, valle del Cauca, Caldas y Sur del Cesar, en la década de los cincuenta, concomitante con la conformación de las Ligas Campesinas Agrarias en el Tolima, sur occidente de Cundinamarca y en la zona de Ariari (Meta), las cuales posteriormente fueron el origen de las Farc (Fuerzas Armadas Revolucionarias de Colombia) (PNUD, 2003, pp.21-28).
Durante el período de guerra partidista entre liberales y conservadores, comprendido entre los años de 1948 a 1953, conocido históricamente como la "violencia", se estima, que más de 300 mil personas murieron de una población que se estimaba de 5 milones de personas. Tras de la guerra no sólo murieron hombres y mujeres, también se presentó una reestructuración de los asentamientos humanos pues millares de campesinos migraron a las ciudades para evitar la muerte, generándose un incremento del número de habitantes en las ciudades del 30\% al 70\% de la población total y el campo quedó reducido al 30\% de la población total colombiana (Umaña, 1989, p. 34).

Es importante resaltar, que desde esa época, comenzaron a darse los primeros brotes de paramilitarismo en Colombia, entendiéndolo como la conformación de ejércitos particulares en busca de la defensa de los intereses partidistas y con el marcado apoyo extralegal del gobierno de turno; grupos armados, como en el caso de los "chulavitas", compuesto por campesinos y obreros conservadores con la anuencia de la policía de Boyacá, y que posteriormente fueron extendiendo su accionar en todo el país, estos grupos fueron responsables de las mayores masacres $y$ asesinatos políticos de la época.

\section{Las amnistías y la "pacificación" de los cincuenta}

En 1953, luego de la toma del poder por parte del General Rojas Pinilla, se constituyó un "Tribunal de Gracia", el cual promulgó leyes y decretos de indulto y amnistías, en favor tanto de militares y grupos de conservadores que habían participado en el golpe de Estado a López Pumarejo en 1944, y que luego, habían defendido a sangre y fuego el poder conservador. Mediante el Decreto 2184 de 1953 se declaró la amnistía para los 
militares y grupos armados conservadores chulavitas. Con los decretos 1823 y 2062 de 1953 se amnistió e indultó a los miembros de las guerrillas liberales. El proceso de amnistía e indulto se dirigió a los combatientes, pero nunca se señaló los autores intelectuales de las luchas que ocasionaron la muerte a cerca del $10 \%$ de la población del país.

Paradójicamente, el período de "paz" sobreviniente luego de las amnistías, fue igualmente sangriento. Se calcula que en el interregno fueron asesinadas 16 mil personas, en su mayoría liberales ex combatientes de los movimientos desmovilizados. A raíz de ésta sistemática persecución y exterminio, muchos de quienes habían integrado las filas de las guerrillas liberales, y ante el acoso estatal realizado particularmente por el ejército, optaron por organizarse nuevamente en núcleos campesinos armados para exigir sus derechos a la tierra, la mejora de vías de acceso y el apoyo estatal con créditos blandos para la producción agrícola, entre otros. Luego del alejamiento de la conducción política de los movimientos armados campesinos, por parte de los directorios partidistas tradicionales, aparecen sectores del partido comunista que intentan definir un objetivo político a estos grupos de alzados en armas de los cuales nace el fervor por consolidar un proyecto campesino y popular de ideología comunista y de resistencia armada, cuyo resultado fue la conformación de las Farc.

Podemos afirmar que el principal componente social de la guerra interna que se inicia en la década de 1960, fue la ausencia de una reforma agraria que impidiera los procesos de concentración de la tierra, lo que ocasionó en el país la ocupación de tierras, por parte de campesinos de las regiones periféricas de Colombia, zonas que se han caracterizado por la no presencia del Estado en todos los órdenes, jurídico, social y de seguridad. Estos procesos de colonización se dirigieron desde 1950 a zonas de las llanuras de la
Costa Pacífica, la Orinoquía y la Amazonía. Para los años de 1970 a 1980, la dinámica de ocupación de la tierra se acelera, producto del desplazamiento forzado, las bonazas lícitas (petróleo, banano, esmeraldas, oro etc.) y las bonanzas ilícitas (contrabando, coca, marihuana) (2003, Pnud, p. 22). Estas nuevas dinámicas produjeron una mayor intensidad del conflicto armado interno en las zonas de colonización.

Adicional al componente social, en Colombia no existieron escenarios políticos desde los cuales se pudieran ventilar controversias, esto ocasionó que muchos lideres políticos de pensamiento socialista desarrollaran su oposición desde la clandestinidad. En particular, el periodo entre 19581974, se constituyó el Frente Nacional, que representó un pacto político entre los partidos tradicionales liberal y conservador de alternación del control del Estado y que impidió la participación en la vida política de otros sectores.

\section{El desarrollo de los movimientos insurgentes en Colombia}

Es en este escenario, en el que confluyen las demandas sociales de campesinos sin acceso a la tierra, la ausencia total del Estado y el cierre político, aparecen los grupo insurgentes ya influenciados por el pensamiento marxista, que buscan suplantar el papel del Estado en cuanto regulador social, y a su vez, proponen cambiar un modelo social, político y económico distinto al Ilamado modelo capitalista.

Estos actores, influenciados por modelos ideológicos y de guerra foráneos, aparecieron a lo largo de la década de los sesenta, se expandieron en los setenta, y han mantenido dinámicas diferentes en su proceso de confrontación con el Estado y consolidación interna, tanto militar como económica. Así, en el país surgieron innumerables grupos insurgentes, de tendencias y pensa- 
mientos ideológicos disímiles, tantos o iguales que los que correspondieron al aflorar mundial de las tendencias políticas de izquierda. Grupos insurgentes con pensamiento maoísta, marxista, guevarista y nacionalista, conformados, según modelos de construcción de guerrilla y estrategias para la toma del poder, por bases campesinas, obreras, estudiantiles o referentes urbanos. En Colombia, a mediados de los ochenta, podrían enumerarse aproximadamente ocho grupos guerrilleros distintos: las Fuerzas Armadas Revolucionarios de Colombia Farc-EP (de pensamiento comunista y ascendencia campesina); el Ejercito de Liberación Nacional (ELN) (de pensamiento guevarista y conformada en sus inicios por estudiantes universitarios); el Ejercito Popular de Liberación (EPL) (de pensamiento maoísta, conformada por disidentes del Partido Comunista); el Partido Revolucionario de los Trabajadores (PRT) (movimiento armado menor, focalizado en el Departamento de Sucre y Bolívar); el Movimiento Indígena Guerrillero Quintín Lame (con accionar principalmente en el departamento del Cauca, conformado por indígenas); el M-19 (nacionalista y con mayor presencia urbana); el grupo guerrillero Autodefensa Obrera (experiencia eminentemente urbana); y la Corriente de Renovación Socialista (deslindada del ELN). La totalidad de estos grupos, a excepción del ELN, las Farc y un reducto del EPL, se han desmovilizado. Esto ocurrió fundamentalmente entre 1990 y 1994. Las desmovilizaciones han sumado aproximadamente 4.691 combatientes. Estas desmovilizaciones se presentaron en un escenario internacional caracterizado por el derrumbe del modelo socialista soviético. En la región latinoamericana con el fin de las dictaduras y una apertura en lo político que daría impulso a la expedición de nuevas constituciones.

El primer grupo insurgente que se acogió en este proceso fue en $M-19$, bajo el mandato del Virgilio Barco (1986-1990), quien en 1990 firma un acuerdo de desmovilización. Posteriormente, en 1991, lo harán el EPL, PRT y el Quintín Lame y finalizaría este proceso con los grupos insurgentes CRS, Milicias Urbanas de Medellín y el Frente Francisco Garnica de la Coordinadora Guerrillera durante el gobierno de César Gaviria Trujillo (1990-1994).

\section{Marco Jurídico de los procesos de desmovilización y negociación}

A continuación se presentará el marco jurídico que se ha construido en el país con el fin de crear escenarios de dialogó con los grupos insurgentes. Este marco legal ha variado de acuerdo a la evolución del conflicto y a las dinámicas internacionales que con el transcurrir del tiempo imponen nuevos requerimientos a los gobiernos, los cuales tiene relación con el respeto al derecho internacional humanitario, al castigo a quienes hubiesen cometido delitos de lesa humanidad y la necesidad de reparación de las victimas.

\section{Gobierno de Belisario Betancur (1982-1986)}

El gobierno del presidente liberal Turbay Ayala, se caracterizó por un alto nivel de represión contra sindicalistas y lideres sociales. Esto ocasionó el repudio nacional e internacional debido a las medidas militares que se plasmaron en el Estatuto de Seguridad, con el cual se autorizó la arbitrariedad generalizada y la práctica de métodos para liquidar las redes urbanas de la guerrillas a través de torturas y violaciones a los derechos humanos de los presos y perseguidos políticos, en un contexto en donde los movimientos insurgentes, en su conjunto, generaron simpatías al interior de la sociedad.

Con el ascenso al poder de Belisario Betancur, en 1982, se genera un nuevo ambiente político y se propician acuerdos para llegar a una paz negociada en los grupos insurgentes de las Farc, el ELN y el M-19. En este contexto, el Congreso 
de la República aprueba, con un solo voto en contra, una ley de amnistía amplia, general y sin condiciones para los alzados en armas que se acogieran a los procedimientos establecidos en esa norma. El proyecto, aprobado, fue la ley 35 del 19 de noviembre de 1982, que prescribía:

Artículo 1. Concédase amnistía general a los autores, cómplices o encubridores de hechos constitutivos de delitos políticos cometidos antes de la vigencia de la presente ley.

Artículo 2. Para los efectos de esta ley, entiéndase por delitos políticos los tipificados en el Código Penal como rebelión, sedición o asonada, y los conexos con ellos por haber sido cometidos para facilitarlos, procurarlos u ocultarlos.

Artículo 3. Los homicidios fuera de combate no quedarán amparados por la amnistía si fueron cometidos con sevicia o colocando a la víctima en situación de indefensión o inferioridad, o aprovechándose de esta situación."

Así se señalaron las categorías de los delitos mencionados cometidos antes del 20 de noviembre de 1982. En virtud de esta ley, efectivamente salió de la cárcel la mayoría de los presos y perseguidos políticos de todas las organizaciones alzadas en armas, quedando solamente unos 20 presos sindicados de homicidio y cuyos hechos no fueron considerados como realizados en combate. La mayoría de las acciones realizadas por los grupos insurgentes hasta inicios de los años ochenta no se dirigieron contra la población civil.

Esta amnistía cobijó a los miembros del M-19 que se habían tomado la embajada de la República Dominicana para exigir la libertad de los presos políticos. Durante esta operación militar se presentaron homicidios, lesiones personales, toma de rehenes, destrucción de bienes, rebelión, etc. Sin embargo, estas conductas se consideraron como actos de combate y propios de la complejidad del delito de rebelión.
Los acuerdos se fundamentaron en una agenda de negociación limitada. Se reconoció efectivamente un cambio en el modelo de tratamiento a los opositores políticos por parte de dicho gobierno. Se discutieron asuntos relativos al desarme, conversión de los movimientos en partidos políticos legales y propuestas de reglas electorales especiales para facilitar su representación en el Congreso. Finalmente, se puso termino a los consejos verbales de guerra para juzgar a los alzados en armas.

En el gobierno de Belisario Betancur se logró una tregua con los grupos insurgentes de las Farc, el M19 y el EPL. Sin embargo, para 1985, se reinician a nivel nacional los combates y se asiste al fortalecimiento del paramilitarismo a la sombra de la impunidad oficial, evidenciada en su articulación con el ejército. En este panorama se expide la ley de indulto No 49 de julio de 1985, que otorgaba amnistía e indulto a los alzados en armas que se acogieran a ella, sin embargo, se limitaba en casos como el secuestro, la extorsión, homicidio fuera de combate y los delitos relacionados con estupefacientes. Este marco legislativo no tuvo efectos prácticos ya que los grupos armados no aceptaron continuar con el dialogo. Sin embargo, por su implicación, reseñamos los apartes fundamentales:

Ley de indulto No 49 del 4 de julio de 1985

Artículo 1. Autorízase al Presidente de la República para que, con base en las facultades que le confiere el ordinal cuarto del artículo 119 de la Constitución, conceda indultos con sujeción a las siguientes reglas:

1. El indulto sólo podrá cobijar a los condenados mediante sentencia ejecutoriada por los delitos de rebelión, sedición y asonada.

2. El indulto podrá extenderse a los delitos conexos con los anteriores, por haber sido cometidos para facilitarlos, procurarlos, consumarlos u ocultarlos, con excepción del secuestro, 
la extorsión, los delitos tipificados en el decreto extraordinario 1188 de 1974 (estupefacientes) y el homicidio fuera de combate, si se hubiere cometido con sevicia o colocando a la víctima en situación de indefensión o inferioridad o aprovechándose de esa situación.

En cuanto a la extensión de la amnistía anterior, se dispuso en el artículo 2 de la misma ley:

“Dispónese cesación de procedimiento en beneficio de quienes, antes del 1 de marzo de 1985, hubiesen cometido alguno de los delitos a que se refiere el artículo primero de la presente ley, con las excepciones allí establecidas, y respecto de los cuales no existiere aún sentencia condenatoria ejecutoriada".

\section{El Indulto de 1989. Preparación de condiciones para la reinserción y la Nueva Constitución de 1991}

El día de su posesión como presidente, Virgilio Barco (1986-1990) fijó las políticas para el inicio del proceso de negociación con los grupos insurgentes: Primero, el control del proceso de paz debe situarse en la rama Ejecutiva. Segundo, el gobierno debe partir de la premisa de que el Estado es la entidad política legítima y que la guerrilla opera por fuera de la ley. Tercero, el Estado puede ser magnánimo y ofrecer amnistías sin embargo, el gobierno no tiene que aceptar a la guerrilla como representante de la sociedad civil. Cuarto, el gobierno no tiene que negociar reformas políticas y sociales con la guerrilla.

Durante los primeros años de la administración Barco, el proceso no arrojó muchos resultados. La reducción de la agenda de negociación constituía un retroceso en la mesa de negociación. Sin embargo, en 1989, cuando sólo faltaba un año para que expirara su mandato, el M-19 se separó de la Coordinadora Guerrillera Simón Bolívar, (CGSB) escenario que reunía a los principa- les grupos insurgentes y aceptó las condiciones previas de Barco, en particular el cese al fuego unilateral.

Igualmente acordó que el resultado final de las negociaciones sería el desarme y la reincorporación política. Esta negociación se presentó en medio de la intensificación de la acción terrorista y el ascenso del paramilitarismo en algunas regiones del país.

Con fundamento en la ley 77 de 1989, se facultó al Presidente de la República para conceder indultos y se regulan casos de cesación de procedimiento penal y de expedición de autos inhibitorios en desarrollo de la política de reconciliación. Los apartes de este decreto se sintetizan en las siguientes normas.

Con fundamento en la ley 77 de 1989, se reinsertan a la vida civil los miembros del M-19 y se crea la Alianza Democrática M-19. Dos semanas después de la entrega de armas, el 26 de abril de 1990, su candidato Presidencial, Carlos Pizarro, fue asesinado en un avión en pleno proceso electoral. Su sucesor, Antonio Navarro, obtuvo el $12 \%$ de la votación a la presidencia y en las elecciones para la Asamblea Constituyente la Alianza Democrática alcanzaría el 30\% de la votación total.

\section{Los procesos de reinserción y los decretos de indulto (1990-1998)}

El camino de la negociación fue seguido por otros grupos insurgentes: el Ejército Popular de Liberación (EPL), el Partido Revolucionario de los Trabajadores (PRT), el Movimiento Armado Quintín Lame (MAQL) y la Corriente de Renovación Socialista (CRS). En efecto, el presidente César Gaviria (1990-1994), negoció el desarme y la reincorporación de estos grupos. Después del desarme, los grupos desmovilizados podrían presentar candidatos a elección popular para la Constituyente. Al PRT y al Quintín Lame se le concedieron únicamente por el gobierno dos representantes. El EPL 
convirtió su movimiento en un nuevo partido político, Esperanza, Paz y Libertad, que terminó fusionado con la AD-M19.

Se expidieron nuevos decretos de indulto ${ }^{1}$ que señalaban que este beneficio sólo borra el delito y la pena, pero sus miembros pueden ser demandados por las víctimas de los delitos y no implica, desde el punto de vista político, el olvido de los "delitos cometidos" en el ejercicio de la rebelión.

\section{Ley 104 de 1993}

En Ley 104 de 1993, el Congreso de la República consagró instrumentos para la búsqueda de la convivencia y la eficacia de la justicia. Consagró las causales de extinción de la acción penal y de la pena en caso de delitos políticos y conexos. Esta Ley cobijó los acuerdos de paz firmados en 1994 entre el Gobierno Nacional y los grupos insurgentes CRS ( 9 de abril), Milicias Urbanas de Medellín (26 de mayo) y el Frente Francisco Garnica de la Coordinadora Guerrillera (30 de junio).

Por medio de este acto legal, se promueve el abandono voluntario individual de personas vinculadas a grupos subversivos, de justicia privada y las milicias populares y promueva diálogos con los grupos insurgentes.

Los beneficios jurídicos concedidos en esta ley no se extendían a la comisión de delitos atroces, el secuestro, el homicidio cometido fuera de combate, ni en general a delitos cuya pena mínima excediera 8 años de cárcel. El marco de beneficios era restrictivo y solo cobijaba delitos políticos como de rebelión, sedición y asonada.

En su artículo 10 toca por primera vez la posibilidad de la reparación, ya que el funcionario judicial de conocimiento, al momento de conceder los bene- ficios jurídicos, podría imponer de oficio la obligación de reparar el daño ocasionado por la comisión del delito solo si el beneficiado pudiese o estuviese en capacidad de hacerlo. Se habla entonces de reparación oficiosa, limitado a los delitos políticos y sin reparación obligatoria.

El artículo 14 de la ley 104, permitió al gobierno realizar diálogos con grupos guerrilleros para buscar la reinserción de sus integrantes a la vida civil. Facultó por primera vez al gobierno nacional para acordar con los voceros o representantes de grupos guerrilleros zonas de ubicación temporal dentro del territorio nacional, con la exclusiva intensión de que las zonas sirvan para facilitar la verificación del cese de operaciones subversivas.

Facultaba al gobierno nacional igualmente, para que, por una sola vez, pudiese nombrar un número plural de congresistas en cada cámara en representación de los grupos desmovilizados, norma de la cual se benefician el EPL y la Corriente de Renovación Socialista.

Esta normatividad se refiere al ejercicio de la reparación patrimonial a las victimas por perjuicios ocasionados por atentados terrorista cometidos por bombas y tomas guerrillas, creándose un fondo de solidaridad para estos aspectos.

Durante este periodo se presentaron las más importantes desmovilizaciones de los grupos insurgentes en Colombia, así:

\begin{tabular}{|l|r|}
\hline Ejército Popular de Liberación (EPL) & 2.000 \\
\hline Movimiento 19 de Abril (M-19) & 900 \\
\hline Partido Revolucionario de Ios Trabajadores (PRT) 200 \\
\hline Movimiento Armado Quintín Lame (MAQL) & 157 \\
\hline Comandos Ernesto Rojas (CER) & 25 \\
\hline Otras organizaciones & 5 \\
\hline TOTAL & 3.287 \\
\hline Www.mindefensa.gov.co
\end{tabular}

1 Decreto 213 del 22 de enero de 1991. Decreto 1943 del 12 de agosto de 1991 y la Ley 104 de 1993. 
Posteriormente, ocurre el proceso de reinserción de una disidencia del Ejército de Liberación Nacional, la Corriente de Renovación Socialista, mediante acuerdo suscrito el 9 de abril de 1994; seguida por las Milicias de Medellín, que incluyó las Milicias Independientes del Valle de Aburra y las Milicias Metropolitanas, las cuales firmaron un acuerdo el 26 de mayo de 1994. El frente Francisco Garnica de la Coordinadora Guerrillera, firma acuerdos el 30 de junio de 1994 y el Movimiento Independiente Revolucionario-Comandos Armados, MIR-COAR, suscribe acuerdos de dejación de armas el 29 de julio de 1998. Los datos de desmovilizados de estos grupos son los siguientes:

\begin{tabular}{|l|c|}
\hline Corriente de Renovación Socialista & 433 \\
\hline Milicias & 650 \\
\hline Frente Francisco Garnica & 150 \\
\hline $\begin{array}{l}\text { Movimiento Independiente } \\
\text { Revolucionario-Comando Armado }\end{array}$ & 171 \\
\hline TOTAL & $\mathbf{1 . 4 0 4}$ \\
\hline
\end{tabular}

www.mindefensa.gov.co

Sin embargo, pese a ello, las guerrillas en las Farc y el ELN no se acogieron al proceso de paz argumentando la ausencia de reformas estructurales que permitieran superar las causas del conflicto debido a que temas como la reforma agraria y el manejo de recursos hidroeléctricos habían sido excluidos de la agenda de negociación. Adicionalmente existía el temor de que se presentara un genocidio similar al ocurrido con la UP, organización política de izquierda nacida de los primeros acuerdos de paz con el gobiernos de Belisario Betancur y que fue aniquilada por grupos de extrema derecha, con anuencia del Estado Colombiano.

\section{LA DEGRADACIÓN DE LA GUERRA}

\section{La violación de los derechos de los no combatientes}

El derecho internacional público ${ }^{2}$ ha desarrollado una serie de convenios internacionales destinados a proteger a las personas y para regular situaciones de guerra. El fin último de estas regulaciones es el respeto a la vida y el cumplimiento de los derechos humanos, tanto de los combatientes como de los no combatientes. En conflictos armados se recurre al derecho internacional humanitario para regular situaciones como: el uso de armas, el trato que se debe dar a los combatientes y la distinción entre combatientes y no combatientes. Esta normatividad conocida como Derecho de Ginebra, se desarrolló a comienzos del siglo XX y ha evolucionado hasta llegar a la suscripción de los protocolos I y II de Ginebra. Adicionalmente, existen los tratados internacionales de derechos humanos y las normas jurídicas de orden interno desarrolladas por los Estados democráticos de Occidente, que prevén la posibilidad de crear estatutos especiales con el fin de superar situaciones que alteren el orden público y castigar a los responsables de la alteración y de proteger a la sociedad civil de los actores armados y en confrontación.

Una característica esencial del Derecho de Ginebra es la distinguir entre combatientes y no combatientes y sobre todo proteger y asistir a las víctimas, a la población civil afectada. Por su parte, el derecho de la Haya busca regular la conducción de las hostilidades y restringir la utilización de los métodos y medios de guerra (Valencia, 1992, p. 42). El derecho internacional humanitario se constituye así en una herramienta indispensable para humanizar los conflictos entre los Estado, lo mismo que los conflictos internos.

2 El derecho internacional de los derechos humanos se agrupa en la actualidad en tres categorías: Los derechos humanos, el derecho internacional humanitario y el derecho penal internacional. 
Sin embargo, en la actualidad existe un nuevo tipo de confrontación, las "nuevas guerras", que son de orden interno y extra estatal. En este tipo de guerras, la violencia es dirigida contra los civiles, se presenta un aumento considerable de las violaciones de los derechos humanos, y en particular del Derecho Internacional Humanitario (DIH) representado en hechos de torturas, desplazamientos, asesinatos indiscriminados, violaciones contra mujeres, reclutamiento de niños. De esta forma, las poblaciones desarmadas se convierten en escenarios de guerra.

La mayoría de los autores coinciden en identificar el terrorismo a partir de dos características fundamentales. En primer lugar, la violencia utilizada por lo general tiene como objetivo a la población civil. En segundo lugar, el uso de la violencia busca causar miedo y terror al interior de toda la sociedad. Estos elementos diferencian al terrorismo de otras manifestaciones de guerra ${ }^{3}$.

El caso colombiano no se escapa de esta dinámica de la guerra. Los no combatientes son con mayor intensidad victimas de acciones de guerra; se presenta de manera continuada la violación permanente y sistemática contra los derechos humanos de personas que son vistas como "colaboradores" o "enemigos" por parte del Estado, de los paramilitares y de los grupos insurgentes. La población civil, en éste contexto, se ha convertido en victima de actos de violencia tan execrables como masacres, asesinatos selectivos, eliminación de movimientos políticos, como el ya señalado en el caso de la UP, desplazamiento y desapariciones forzadas.

Uno de los elementos más importantes en el presente análisis es observar como el conflicto armado interno que vive Colombia ha venido per- diendo la lógica política de parte del los grupos insurgentes, en particular de las Farc-EP, prevaleciendo la lógica militar y una economía de guerra que se nutre de los secuestros, las extorsiones y el narcotráfico.

Por parte de las autodefensas, organizaciones vinculadas a grupos terratenientes locales y al narcotráfico, se caracterizan por haber desarrollado una lucha contrainsurgente que tiene como objetivo el control territorial de zonas de producción de estupefacientes y de tierras de producción agrícola. Estos grupos ven como principal enemigo a la población civil que señalan la mayoría de las veces como auxiliadores de la guerrilla. A los grupos paramilitares se les adjudica el mayor número de masacres, asesinatos, ejecuciones sumarias, torturas, abusos sexuales y desplazamientos ocurridos en el país.

La guerra en Colombia a partir de la segundad mitad de la década de 1980 , ha venido adquiriendo una dinámica de degradación permanente, producto del uso sistemático de actos de terrorismo que va en contravía de las reglas del derecho humanitario. Esta lógica esta unida al deseo de controlar territorios y de eliminar cualquier tipo de oposición en estos y la de destruir las "bases sociales" del enemigo.

La barbarie de la guerra se demuestra en la violación continuada y sistemática contra los derechos humanos de millones de personas que son vistos como "colaboradores" o "enemigos" por parte del Estado, de los paramilitares y de los grupos insurgentes. La población civil en éste contexto, se ha convertido en victima de actos de violencia. Entre 1988 y el 2003 cerca de 33 mil personas han sido víctimas de masacres, de las cuales el $70 \%$ son atribuidas a los grupos de

3 Pizarro Leongomez, Ibíd, p. 134. 
paramilitares. En el mismo periodo, se han presentado alrededor de 12.398 asesinatos selectivos, los cuales en su mayoría fueron realizados por los grupos de autodefensas. Se calcula en el mismos lapso, cerca de 2 millones 500 mil personas han sido desplazadas por razones del conflicto armado interno, la mayoría de los desplazamientos han estado motivados en el temor o en las amenazas del paramilitarismo.

El uso de "carros bombas", cilindros de gas y minas antipersona, que no discriminan el combatiente del no combatiente, $y$ finalmente, el secuestro que se ha convertido en un medio de negociación y de obtención de recursos por parte de los actores armados, particularmente de las Farc-EP. El canje de secuestrados en poder de las Farc a cambio de sus presos en las cárceles del país, es la principal bandera que en la actualidad utiliza este grupo insurgente para promover procesos de dialogo y negociación en el gobierno.

Estas prácticas recurrentes de los actores armados, que tienen como objetivo a los no combatientes, la mayoría personas indefensas, han generado en la sociedad un efecto de terror y pánico colectivos y son el motivo por el cual la mayoría de la población colombiana percibe la política de seguridad del gobierno de Álvaro Uribe Vélez como una vía a la solución del conflicto interno frente a las acciones terroristas la sociedad tiende a polarizarse y a escoger la vía de la "seguridad" como mecanismo para resolver el conflicto.

Adicionalmente, a los actos terroristas los grupos armados al margen de la ley han necesitado incrementar sus rentas con el objetivo de sostener el aparato militar cada vez más numeroso. Para ello, ha recurrido a nuevas prácticas, entre las que sobresalen la extorsión y la producción y comercialización de cocaína como fuente de recursos.
En la actualidad el terrorismo y el narcotráfico son en la agenda internacional objetivos prioritarios, lo cual ubica a Colombia en el debate regional, en particular alrededor de la caracterización de los actores armados y de los efectos que el conflicto trae en los países vecinos los mismo que a EE. UU. y a Europa, ya sea por la comercialización drogas ilícitas, por la crisis humanitaria que produce la guerra interna o por los escándalos de corrupción que traspasan la fronteras, ligados al contrabando de armas, o a la vinculación de políticas en narcotraficantes y grupos para militares.

De lo anterior se han generado continuos debates entorno a entender cual es el significado del conflicto interno colombiano y como caracterizar a los grupos armados. Se quiere saber si se enfrenta el país a una lucha contra el terrorismo o es una lucha contrainsurgente. En estas discusiones existe la tendencia de catalogar a todos los actores armados como grupos terroristas o a distinguir los actores del conflicto a partir de sus motivaciones y de sus prácticas. Sin embargo, la degradación de la guerra conducta, cada vez más, a caracterizar a los actores del conflicto como terroristas.

Las Autodefensas Unidas de Colombia se proclaman como un grupo contrainsurgente, amparado en una ideología de extrema derecha. Su método de acción ha estado dirigido contra la población civil sobre la cual han recaído masacres, asesinatos selectivos, desplazamiento y el exterminio a partidos de izquierda como la UP. De manera sistemática desde 1988 las autodefensas han generado el terror sobre amplios sectores de la sociedad a los cuales consideren como auxiliadores de la guerrilla. Por los métodos que utilizan las AUC son consideradas inequivocadamente como una organización terrorista 4 .

$4 \quad$ Pizarro Leongómez, Ibíd, p. 149. 
Con relación a las Farc-EP y al ELN, estos grupos insurgentes tienen su origen en la década de los sesenta, inspirados en un pensamiento de izquierda que promulgaba una transformación de las estructuras políticas, sociales y económicas. Su método de acción se caracterizó por la estrategia de la llamada "guerra de guerrillas". Sin embargo, desde la última década del siglo XX, sus métodos se han transformado; se incrementan las acciones que involucran a la población no combatiente como el uso de carros bomba, minas antipersona, el uso de cilindros de gas y el secuestro. Todo ello conduce a hacer cada vez más difusa la diferencia de una organización insurgente con una organización terrorista. En la actualidad estas organizaciones combinan las acciones propias del la lucha guerrilla con acciones terroristas. Este tipo de prácticas han venido perdiendo legitimidad, tanto dentro de la sociedad colombiana como frente a la comunidad internacional, de tal manera que estas organizaciones han venido siendo incluidas en las listas de organización del gobierno Norteamericano, lo mismo que por la Unión Europea.

En este escenario de permanente degradación del conflicto armado, el gobierno de Álvaro Uribe Vélez (2002-2006), decidió iniciar un proceso de negociación con los grupos paramilitares. Para ello, se vio en la necesidad de crear un marco legislativo, que en medio de la barbarie del conflicto, fuera aceptado por la comunidad internacional.

\section{MARCO JURÍDICO EN EL PROCESO DE NEGOCIACIÓN CON LOS GRUPOS PARAMILITARES}

\section{Gobierno de Álvaro Uribe Vélez (2002- 2006), Ley 975 de 2005 y decreto 128 de 2003}

Álvaro Uribe Vélez asumió la presidencia de Colombia el 7 de agosto de 2002, en medio de un ambiente de escepticismo por el fracaso de las negociaciones entre el gobierno de Pastrana y la guerrilla de las Farc. La política de Uribe se ofreció al país con el nombre de la Seguridad Democrática. Esta política tiene tres componentes básicos: primero, la lucha frontal contra las Farc que es catalogada por el presidente como un grupo terrorista que se nutre del narcotráfico. En segundo lugar, se vincula más a la población civil con el conflicto armado al proponer la creación de una red de informantes que denuncien el accionar de la guerrilla a cambio de recompensas en dinero. Por último, promueve una negociación con lo grupos armados de extrema derecha.

Para el desarrollo de este proceso de negociación fue necesario la creación de un marco jurídico que ha reglamentado las desmovilizaciones en Colombia, conformado por un grueso número de leyes y decretos, de los cuales podríamos resaltar la Ley 104 de 1993 desarrollado por el Decreto 1385 de 1994; la Ley 418 de 1997 prorrogado por el Decreto 548 de 1999; la Ley 782 de 2002 reglamentado y prorrogada por el Decreto 128 de 2003, y los Decretos reglamentarios 3360 de 2003 y 2767 de 2004; y la ley 975 de 2005 y su respectivo Decreto reglamentario 4760 de 2005.

De estos instrumentos jurídicos destacaremos el decreto 128 de 2003 y la ley 975 de 2005, conocida como "ley de justicia y paz".

La ley 975 tiene como propósito el desarrollo de unos mecanismos para la reincorporación de los grupos armados al margen la ley con el fin de conseguir la paz y se aplicará a las personas que han cometido actos que no pueden recibir el indulto o ser amnistiados como delitos de lesa humanidad, secuestro, narcotráfico, terrorismo y crímenes de guerra. La ley está compuesta por XII capítulos y 72 artículos. En ella, se establecen los principios de verdad, justicia y reparación; las condiciones para la desmovilización (capitulo II artículo 10); la implementación de un procedimiento enmarcado en los principios del sistema 
acusatorio, en particular la oralidad, un tribunal y una fiscalía especial que se encargará de la investigación y el juzgamiento (Capitulo IV); la creación de una pena alternativa (Capitulo V); se señalan las instituciones que estarán comprometidas en la ejecución de la ley (Capitulo VII); la reparación de las victimas (Capitulo IX) y la conservación de los archivos con el fin de mantener la memoria de lo ocurrido (Capitulo X).

\section{Aspectos relevantes de la Ley 975 de 2005}

Los aspectos de la ley que más resalta el gobierno y que al mismo tiempo son los más cuestionados por distintas organizaciones de la sociedad civil y por las organizaciones de victimas, se concentran en los siguientes puntos: los derechos de las víctimas a la verdad, justicia y reparación; el tema de la alternatividad Judicial, la capacidad de la administración de justicia en responder adecuadamente a las investigaciones en los tiempos previstos y la proporcionalidad de los castigos.

Adicionalmente y quizá sea este el aspecto de mayor preocupación, es si se esta dando o no el desmonte del poder paramilitar, el cual va más allá de la entrega de armas y se manifiesta en control en el poder local, económico y social que poseen los líderes paramilitares.

Con relación a la ley 975 de 2005, los elementos de verdad, justicia y reparación responden, en gran medida, a estándares internacionales. Sin embargo, la realización de estos principios ha sido fuertemente cuestionada por organizaciones de la sociedad civil y por organizaciones de victimas de la violencia por considerar que la Ley y sus decretos reglamentarios no obligan a los integrantes de los grupos de autodefensas a confesar todos sus crímenes.

Con relación a la reparación, se manifiesta por parte de las ONG que la ley no exige la devolución de todos los bienes adquiridos ilícitamente por los grupos de paramilitares, en particular en temas como la tierras y vivienda, así como la dificultad para establecer los daños morales y el lucro cesante. El fondo de reparación a las victimas creado para este fin es insuficiente y no cuenta con los recursos necesarios ya que sus fuentes provienen de las entregas voluntarias que de los bienes realicen los grupos de paramilitares, los recursos no cuantificados del presupuesto de la nación y los portes de la comunidad internacional.

Con respecto a la ley, se promovieron varias acciones de inconstitucionalidad con respecto a los cuales la Corte Constitucional falló situaciones entre otras cosas:

En cuanto al derecho de las víctimas a la reparación integral, la Corte reiteró que esta corresponde a los responsables de los delitos, los cuales habrán de responder con su propio patrimonio, sin perjuicio de que el Fondo de Reparación constituido incluso por recursos del presupuesto nacional cumpla con sus deberes en punto a impedir que las víctimas no reciban una indemnización efectiva. Al respecto, la Corte condicionó la exequibilidad del artículo 54 en el sentido de que todos y cada uno de los miembros del grupo responden con su patrimonio para indemnizar a cada una de las víctimas de los delitos por los cuales fueron condenados pero también responderán solidariamente por los daños ocasionados a las víctimas por otros miembros del grupo armado al cual pertenecieron.

La ley señala en su artículo 17, que el paramilitar deberá rendir versión libre y espontánea ante los fiscales delegados. El fiscal delegado tiene el deber de interrogar al desmovilizado sobre todos los hechos de que tenga conocimiento. El desmovilizado deberá señalar las circunstancias de modo, tiempo y lugar en que haya participado en los hechos delictivos y en la misma debe indicar los bienes que entregará para la repara- 
ción. El artículo 25 permitía al procesado omitir o no declarar todos los crímenes cometidos, ya que con esta omisión no se perdería ningún benefició que otorgase la ley.

Con relación a la alteración de la verdad, han existido diversos reclamos. En primer lugar, se trata simplemente de una verdad judicial que involucra únicamente al que esta siendo procesado. Lo anterior, no daría cuenta de cómo funcionó la estructura paramilitar y de cómo diferentes sectores que del Estado, la economía y sectores políticos apoyaron las estructuras del paramilitarismo. Es decir, existirá una verdad a medias. Otro reclamo recurrente es que no se obliga al desmovilizado a confesar de forma inmediata todos los crímenes de lesa humanidad, torturas, actos de terrorismo y masacres en los cuales hubiese participado. Por último, se cuestiona la baja capacidad de la Fiscalía General para investigar los hechos, la debilidad de las organizaciones de victimas en la recolección de pruebas y los tiempos tan reducidos para la investigación, que tan solo es de 60 días.

Al respecto las demandas interpuestas ante la Corte Constitucional sobre el tema, se resolvieron de la siguiente forma: se declaró inconstitucional el segmento del artículo 25 que permitía ser beneficiario de la pena alternativa, a pesar de haber omitido revelar ante el fiscal su participación en hechos distintos a aquellos por los cuales se le había impuesto la pena alternativa, porque ello representa una afectación manifiesta y desproporcionada del derecho de las víctimas a conocer la verdad. En ese mismo sentido, para garantizar dicho derecho a la verdad, la Corte condicionó la exequibilidad del artículo 17, sobre las características de la versión libre ante el fiscal y la exequibilidad del artículo 29, en punto a la revocación del beneficio de la pena alternativa.

Con esta sentencia se obliga al desmovilizado de cualquier grupo paramilitar a declarar en la versión libre todos los actos cometidos durante el tiempo en el que permaneció en dicho grupo. Sin embargo, con ello poco se logra conocer acerca de que grupos o personas promovieron apoyaron y auxiliaron la conformación de estos grupos.

La ley en los artículos 3, 24 y 29 se establecen los conceptos y características de la alternatividad penal señala la ley en su articulo 3 que "es un beneficio consistente en suspender la ejecución de la pena determinada en la respectiva sentencia, reemplazándola por una pena alternativa que se concede por la contribución del beneficiario a la consecución de la paz nacional, la colaboración con la justicia, la reparación a las víctimas y su adecuada resocialización." Las penas establecidas es de mínimo cinco 5 años y un máximo de ocho 8 años. Además, la ley computará como tiempo de ejecución de la pena el transcurrido durante la concentración en la zona de desmovilización y dialogo, que sumará hasta de 18 meses. Por último, los lugares en los cuales se hará la reclusión serán "Colonias Agrícolas". A pesar de los innumerables cuestionamientos por parte de organizaciones de víctimas, en los cuales se señala la falta de proporcionalidad que conlleva la sanción frente a la gravedad de los hechos, cuestionándose, por tanto, el alto costo de la paz al tener que ceder en la aplicación de una justicia proporcional, la Corte declaró exequible lo relacionado con el mecanismo de la alternatividad penal consagrado en la ley.

\section{El Decreto 128 de 2003}

Este decreto estableció diversos beneficios para los desmovilizados. El principal de ellos, contenido en el artículo 13, señala:

Beneficios jurídicos. De conformidad con la ley, tendrán derecho al indulto, suspensión condicional de la ejecución de la pena, la cesación de 
procedimiento, la preclusión de la instrucción o la resolución inhibitoria, según el estado del proceso, los desmovilizados que hubieren formado parte de organizaciones armadas al margen de la ley...

Al Decreto 128 de 2003, artículo 13, se acogen 31.421 combatientes que no tenían procesos pendientes, ni condenas. En estos casos el gobierno se ha abstenido de iniciar cualquier actuación investigativa y hasta la fecha de esta ponencia no se ha tomado ni iniciado un solo acto de investigación que involucre a los combatientes de los grupos paramilitares en delitos como desapariciones, asesinatos, masacres, desplazamientos, narcotráfico o terrorismo. Durante la entrega de los desmovilizados no se practicó con ninguno de ellos versión libre.

\section{CONCLUSIONES}

Hasta el 2005, los distintos gobiernos del país implementaron como formula jurídica para la desmovilización de los grupos alzados en armas la amnistía y el indulto. En procesos de paz anteriores se presentaron iniciativas muy tímidas o insuficientes que buscaron la reparación, proscribiendo, a demás, la posibilidad de indultos o amnistías por la comisión de delitos atroces. En los procesos jurídicos anteriores al 2005, la mayoría de las víctimas no fueron escuchadas en sus reclamos. Con la desmovilización del M-19, durante el gobierno del presidente liberal Virgilio Barco, se recurrió a la figura del indulto y, posteriormente, cuando algunos congresistas intentaron iniciar un debate sobre la responsabilidad política de dicho grupo el llamado el "holocausto" del Palacio de Justicia, el Gobierno decretó nuevamente un indulto a los comandantes del movimiento desmovilizado.

El proceso de desmovilización de los grupos paramilitares y la posterior aplicación de la Ley de Justicia y Paz, implica un nuevo marco jurídico que busca responder a estándares internacionales, sin embargo, frente a la referida ley existe el temor de que detrás de ella se pueda presentar un proceso de impunidad, en la medida que, teniendo en cuenta las propias cifras dadas por la Oficina del Alto Comisionado para la Paz, de un total de los 33.601 desmovilizaciones en el marco de las negociaciones con las autodefensas, tan sólo a 2180 se les aplicará la Ley de Justicia y Paz, por lo que a los 31421 restantes se les dictaría amnistía o indulto y/o serían cobijados por beneficios judiciales como la resolución de preclusión de la investigación, cesación del procedimiento o resolución inhibitoria, según lo reglado por el Decreto 128 de 2003. Los datos del universo de desmovilizados a los cuales se les aplicaría también la ley 975 de 2005, se aumenta en la medida que, hasta la fecha hay 2000 solicitudes de aplicación de la Ley por parte de personas detenidas o condenadas por delitos atroces atribuibles al paramilitarismo.

La ley 975 de 2005 y el decreto 128 de 2002 que se promulgaron con el objetivo de alcanzar la culminación de conflicto armado ofrece importantes falencias. En primer lugar, en la mayoría de los casos los victimarios quedan en total impunidad frente a los actos de violencia cometidos, impunidad que cobija no solo a los actores materiales, sino que se extiende a los actores intelectuales que han propiciado la intensificación y degradación del conflicto armado. En segundo lugar, la reparación real en el actual proceso de negociación no se presenta como un aspecto que se pueda materializar ya que hasta el momento no se existen la voluntad de entrega de los bienes usurpados por los paramilitares. Finalmente, la estructura del paramilitarismo no se ha desarticulado plenamente, pues tanto el control territorial como la vigencia en el poder político local, e inclusivo nacional, permanecen intactos. 
Las organizaciones de víctimas y defensores de derechos humanos vienen cuestionando las eficiencias de la ley de justicia y paz con respecto a ella se han planteado diversas: estrategias una es tratar de corregir las fallas de la misma lo cual se ha logrado parcialmente por medio del ejercicio de demandas de inconstitucionalidad. La otra, consistía en la implementación de otras estrategias de corte legal para la reparación, como las acciones públicas colectivas y el uso de mecanismos no institucionales de la verdad como los tribunales de opinión. Aun así, el temor sobre la cotidianidad del paramilitarismo con sus estructuras de poder todavía unificado, sigue girando sobre este proceso, sobre las incógnitas que plantea para la democracia Colombiana.

\section{BIBLIOGRAFÍA}

Molano, A. (1985). Los años del Tropel: relatos sobre la violencia. Bogotá: Cerec-Editorial Presencia.

Programa de las Naciones Unidas para el Desarrollo. (2003) Orígenes, guerra en la periferia. En El conflicto callejota con salida. Bogotá: Autor.

Salazar, G. Una mirada crítica al conflicto armado colombiano.

Umaña, E., Villar, L. \& Fals Borda, O. (1963). La Violencia en Colombia.

Valencia V. (1992). La humanización de la guerra. Tercer Mundo Editores.

Paginas Web:

Consejería para los Derechos Humanos de CoIombia. (1995). Comisión de Investigación de
Ios Sucesos Violentos de Trujillo. Informe Final. Bogotá: Imprenta Nacional. Bogotá.

Ortiz Palacios, I. (1999). El Genocidio contra la Unión Patriótica. Universidad Nacional. de Colombia.

http://web.amnesty.org/library/index/ ESLAMR230192005.

Centro de Investigación y Educación Popular. Colombia: Los Paramilitares en Medellín ¿Desmovilización o legalización?.

Banco de datos. Serie Noche y Niebla.. Paramilitarismo de estado en Colombia. Deuda con la Humanidad. Colección panorama de D.H. y Violencia Política en Colombia. Bogotá. 2004.

Las Autodefensas y la Paz. Carlos Castaño. (1999). Colombia Siglo XXI.

h t t p : / w w w . cerac.org.co/pdrf/ briefing_colombian_conflict.pdf.

Almario, O. et al (2004). Dimensiones Territoriales de la Guerra y la Paz. Universidad Nacional de Colombia. Bogotá.

Oficina del Alto Comisionado para la Paz en Colombia. (1998). El Proceso de Paz en Colombia 1982-1994. Tomo I. Compilación de Documentos. Bogotá.

Chandía Castilla, C. El Conflicto Armado y las Manifestaciones de Violencia en la Región de Colombia. Biblioteca Para la Paz.

www.ilsa.org.co 